\title{
UNASUL: a dimensão política do novo regionalismo sul-americano
}

\author{
Tiago Nery*
}

\begin{abstract}
Na primeira década do século XXI, a ascensão de forças progressistas possibilitou a adoção de políticas externas mais autônomas pelos países da América do Sul. A hegemonia neoliberal e os modelos homogêneos de integração dos anos 1990 foram sucedidos por tipos heterogêneos de regionalismo. Entre as novas organizações, a Unasul constitui um fórum de coordenação política que envolve a cooperação em diferentes áreas. Trata-se da vertente política do novo regionalismo sul-americano. Em seu interior, convivem governos com distintos signos ideológicos, que participam de diferentes mecanismos integrativos. A Unasul representa o coroamento de um processo de afirmação de uma identidade sul-americana possível contra a histórica pulverização da região. O novo organismo pode converter-se em um mínimo denominador comum regional. Além disso, a Unasul projeta geopoliticamente a América do Sul e contribui para a construção de um novo polo no sistema internacional.
\end{abstract}

Palavras-chave: Unasul. Política externa brasileira. Regionalismo. Relações internacionais. América do Sul.

\section{INTRODUÇÃO}

O início do século XXI foi marcado por um sentimento de esperança em toda a América do Sul. Após os regimes militares e os governos neoliberais que os sucederam, partidos progressistas - de esquerda ou nacionalistas assumiram o poder nos principais países da região. No âmbito doméstico, os governos eleitos implementaram políticas econômicas mais intervencionistas e políticas sociais responsáveis por retirar milhões de pessoas da extrema pobreza. No plano internacional, os novos líderes adotaram políticas externas mais autônomas e propuseram a construção de um regionalismo diferente, marcado pela heterogeneidade e por seu caráter político, cuja principal expressão é a União de Nações Sul-Americanas (Unasul).

Diferentemente de outros instrumentos de integração econômica e comercial, a Unasul é um espaço multilateral de coordenação e cooperação política. Uma de suas principais características é a pluralidade ideológica

* Secretaria de Estado de Planejamento e Gestão - SEPLAG. Rua Erasmo Braga, 118, sala 713. Cep: 20020-000. Centro Rio de Janeiro - Rio de Janeiro - Brasil. tiagonnery@hotmail.com dos seus membros. Participam da nova organização países com distintos signos ideológicos e diferentes esquemas integrativos, como a Aliança Bolivariana para os Povos da Nossa América - Tratado de Comércio dos Povos (Alba), a Aliança do Pacífico e o Mercado Comum do Sul (Mercosul). Se, para alguns países, a Unasul é um lugar de resistência frente ao poder dos Estados Unidos, para outros, trata-se apenas de um foro multilateral de ação coordenada. Independentemente das divergências, a Unasul tem sido reconhecida como uma instância para a negociação das crises políticas sul-americanas, que já não precisam ser resolvidas pela Organização dos Estados Americanos (OEA). Ademais, em seu processo de criação, deve-se destacar a atuação dos governos brasileiro e venezuelano. Conquanto diferentes, as diplomacias de Lula e Chávez contribuíram para superar alguns obstáculos históricos à integração, ao colaborarem decisivamente para a criação da Unasul.

Como afirma Celso Furtado (2007), a formação de uma consciência latino-americana é um fenômeno recente, resultante dos problemas colocados pelo desenvolvimento econô- 
mico e social da região após a Segunda Guerra Mundial. Naquela época, a criação da Comissão Econômica para a América Latina e o Caribe (Cepal) foi fundamental para o advento e a consolidação de uma consciência regional. Foi um momento em que a América Latina deixou de ser uma expressão geográfica para converter-se em realidade histórica. Apesar da oposição dos Estados Unidos ao seu surgimento, a Cepal resistiu, criou um pensamento original e instalou sua sede em Santiago do Chile, em aberto contraste com os órgãos pan-americanos situados em Washington.

Com sede em Quito, apesar de suas diferenças com a Cepal, a Unasul também representa um momento de afirmação da autonomia sul-americana. Parafraseando Hélio Jaguaribe (1954), ela contribui para romper com a absurda tese de que os países da região só devem se relacionar entre si mediante os mesmo vínculos que relacionem cada um deles aos Estados Unidos.

No belo romance histórico $O$ general em seu labirinto, no qual Gabriel García Márquez relata os últimos dias de Simón Bolívar, há uma passagem em que o libertador discute com um europeu e afirma: "Não tentem nos ensinar como devemos ser, não tentem nos tornar iguais a vocês, não pretendam que façamos em vinte anos o que vocês fizeram tão mal em dois mil" (Márquez, 2014, p. 130). Após muitas tentativas frustradas, os governos e os povos da América do Sul voltaram a buscar novos caminhos para . aproximar os países da região. Nesse esforço, 我 a Unasul pode se transformar em um possível ¿. mínimo denominador comum regional, além de § contribuir para a consolidação de uma polaridary de sul-americana no sistema internacional.

คิ

A POLIITICA EXTERNA BRASILEIRA PARA A AMÉRICA DO SUL

Desde os processos de independência, o Brasil possui características políticas, culturais e territoriais que o distinguem dos demais países hispano-americanos. O país foi capital do Impé- rio português e adotou um regime monárquico em meio a vizinhos republicanos. No século XIX, a monarquia foi a base da singular identidade internacional do Brasil. O país era uma grande massa territorial de fala portuguesa, que havia permanecido unida, enquanto o mundo hispânico se fragmentava e os Estados Unidos se expandiam territorialmente.

A sociedade e a cultura brasileiras foram conformadas como variantes da versão lusitana, enriquecidas pelas contribuições dos índios e dos negros. Segundo Darcy Ribeiro (1995), conquanto diferenciados em suas matrizes raciais e culturais, os brasileiros se sabem, se sentem e se comportam como uma só gente. Trata-se de uma entidade nacional que fala uma mesma língua, diferenciada apenas por sotaques regionais, menos remarcados do que os dialetos de Portugal. Ao contrário da Espanha ou da Guatemala, que são sociedades multiétnicas regidas por Estados unitários, os brasileiros integram uma única etnia nacional, constituindo um só povo incorporado em uma nação unificada, em um Estado uniétnico. A única exceção são as múltiplas microetnias tribais, que não podem afetar a macroetnia em que estão contidas. Ademais, as elites brasileiras lograram manter a unidade territorial. Nesse sentido, é grande o contraste entre o bloco unitário resultante da América portuguesa e o mosaico de quadros nacionais diversos a que deu lugar a América hispânica. O resultado é que o Brasil possui uma área geográfica de $8.500 .000 \mathrm{~km}^{2}$, que corresponde a $48 \%$ da área total da América do Sul, e faz fronteira com dez países, totalizando mais de $15.000 \mathrm{~km}$ de extensão (Guimarães, 2006; Ribeiro, 1995).

Apesar das diferenças identitárias, a importância da política externa brasileira para a América do Sul era percebida com clareza ao tempo do Império. As fronteiras do Estado eram ainda indefinidas, e os interesses geopolíticos do Brasil se concentravam na região do Prata. A história da centralização do poder e da criação dos Estados nacionais na América do Sul, em especial na região geopolítica do Cone 
Sul e na região geoeconômica da Bacia do Prata, possui similitudes com o processo ocorrido na Europa. Dentro desse território relativamente contínuo, as guerras de independência e civis, que se sucederam entre a primeira metade do século XIX e o fim da Guerra do Paraguai (1864-1870), geraram efeitos análogos àqueles produzidos nos países europeus. ${ }^{1}$ Após um período de conflitos e de definição de fronteiras, as rivalidades geopolíticas entre Brasil e Argentina se prolongaram até a segunda metade do século XX. Assim, o Brasil reestabeleceu um século depois, por meios diplomáticos e econômicos, a hegemonia que mantivera na Bacia do Prata até 1876, quando foi superado pela Argentina. Com o aumento da disparidade estratégica, rompeu-se, em favor do Brasil, o equilíbrio de poder na América do Sul (Fiori, 2014; Guimarães, 2006; Moniz Bandeira, 2010a, 2010b).

A americanização das relações exteriores brasileiras ocorreu somente com a República. Esse processo procurou desfazer a percepção de que o Brasil era o diferente da América, em função das suas instituições monárquicas e do que isso significava em termos de ligações políticas e econômicas com a Europa. Nos primeiros anos de governos republicanos, a diplomacia brasileira atuou tendo em conta dois cenários: um sistema americano, liderado pelos Estados Unidos, e um subsistema sul-americano, no qual o país dispunha de uma autonomia relativa. Desse modo, o Brasil resguardava a América do Sul como sua esfera de influência e abstinha-se de qualquer envolvimento na América do Norte, Central e Caribe, por constituírem uma área de hegemonia norte-americana (Lafer, 2004; Moniz Bandeira, 2010a; Santos, 2005).

Desde o final do século XIX, o cerne da política externa norte-americana tem sido afir-

${ }^{1}$ No Cone Sul, do outro lado da cordilheira dos Andes, o Chile conquistou parte do seu atual território após derrotar a Bolívia e o Peru na chamada Guerra do Pacífico (1879-1883). Além dessa contenda ao norte, o Chile avançou sobre as populações e os territórios indígenas ao sul, transformando-se em um dos Estados nacionais que mais cedo se centralizou e militarizou em toda a América do Sul (Fiori, 2014). mar sua hegemonia no Hemisfério Ocidental, ${ }^{2}$ com destaque para sua área geográfica mais próxima, que é a sua zona estratégica mais importante. Dentro da América Latina, a América do Sul apresenta uma maior relevância geopolítica na estratégia dos Estados Unidos, devido ao enorme potencial econômico e político do subcontinente. O principal objetivo estratégico da política externa estadunidense é impedir o surgimento de um polo de poder alternativo no Cone Sul, capaz de questionar sua hegemonia hemisférica. Por suas dimensões geográficas, demográficas e econômicas, o Brasil convertese no único possível rival à influência dos Estados Unidos na região. Como afirma Samuel Pinheiro Guimarães (2006, p.275),

\begin{abstract}
Para que o Brasil e a América do Sul [...] possam ser capazes de defender efetivamente seus interesses de longo prazo em um mundo instável, violento e arbitrário, é indispensável trabalhar de forma consistente em favor da emergência de um sistema mundial multipolar no qual a América do Sul venha a constituir um dos polos e não ser apenas uma sub-região de qualquer outro polo econômico ou político.
\end{abstract}

Uma das preocupações centrais da política externa dos Estados Unidos sempre foi evitar o surgimento de uma América do Sul integrada, com identidade própria, capaz de se contrapor à tradicional política estadunidense de balcanização do subcontinente. Os Estados Unidos estavam conscientes de que a América do Sul gozava de uma relativa autonomia que não era compartilhada pelos países centro-americanos e caribenhos. Ademais, os estadunidenses sabiam que os grandes Estados sul-americanos - Argentina, Brasil e Chile - poderiam contrabalançar seu poderio por meio de ações concertadas e de relações diplomáticas com potências de fora da região. Por isso, o De-

2 Segundo Leslie Bethell (2010), no início do século XIX, o presidente Thomas Jefferson e o senador Henry Clay foram os primeiros a conceber a ideia de "hemisfério ocidental". Posteriormente, os EUA promoveriam o conceito de pan-americanismo, com sua ênfase em uma história e uma geografia compartilhadas, além dos ideais republicanos. Ademais, fariam uma tentativa de institucionalizar a ideia de "hemisfério ocidental", as Américas, como região separada da Europa, em uma série de conferências envolvendo os Estados do continente americano. 
partamento de Estado procura dificultar o processo de integração, fomentando disputas internas, e busca minar iniciativas regionais que não servem a seus desígnios. Daí a estratégia de manter afastados um do outro Brasil e Argentina, de estimular sentimentos de rivalidade e de acenar com alianças privilegiadas com cada país alternadamente, objetivando impedir a união de ambos na defesa e na promoção de seus interesses (Botelho, 2013; Guimarães, 2006; Moniz Bandeira, 2010a).

No início do século XX, o Barão de Rio Branco propôs o Tratado do ABC, envolvendo Argentina, Brasil e Chile. Assinado em 1915, sem o caráter de aliança como pretendera Rio Branco, o tratado desagradou aos Estados Unidos porque poderia resultar na formação de um bloco no Cone Sul. No primeiro governo Getúlio Vargas (1930-1945), houve outra tentativa de aproximação entre Brasil e Argentina, com o intuito de criar uma união aduaneira aberta à adesão dos países limítrofes. A decisão brasileira de entrar na Segunda Guerra Mundial reverteu a parceria, aproximou o Brasil dos Estados Unidos e renovou a rivalidade entre os dois países sul-americanos. Nos anos 1950, o governo de Juan Domingo Perón (1946-1955) retomou a ideia do Pacto ABC. Apesar de simpatizar com a proposta, Vargas enfrentava uma grave crise em seu segundo mandato (19511954), o que acabou comprometendo a iniciativa (Moniz Bandeira, 2010a; Santos, 2005).

సे A contribuição decisiva para a afirmação da identidade latino-americana ocorreu com a

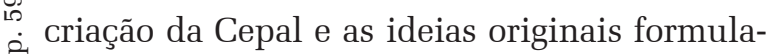
\& das durante sua primeira década, entre $1947 \mathrm{e}$ 돈 1959, por uma equipe de renomados intelectua ais como Raúl Prebisch e Celso Furtado. O penoे samento cepalino, articulado tacitamente com $\vec{i}$ a agenda Norte-Sul, foi determinante para a latino-americanização da política exterior brasileira, que seria reforçada pela Política Externa Independente (PEI) no início dos anos 1960. A partir de então, o processo de integração latino-americano tornou-se uma sucessão de tentativas, erros, avanços e recuos. Com a re- democratização, a identidade latino-americana foi inscrita na própria Constituição Federal de 1988 (Costa, 2010; Lima, 2013; Santos, 2005).

A primeira tentativa mais ambiciosa de institucionalizar a integração ocorreu com o lançamento da Associação Latino-Americana de Livre Comércio (Alalc), em 1960. O Tratado de Montevidéu, que criou a associação, visava a constituir uma zona de livre comércio, com o objetivo de contornar o problema da dimensão dos mercados nacionais da região, conforme diagnóstico da Cepal. As contradições entre países com diferentes graus de desenvolvimento e os regimes militares condenaram a Alalc ao ocaso. O surgimento do Pacto Andino, em 1969, foi uma resposta direta a seu fracasso. Com uma proposta de integração mais ampla, o Pacto Andino objetivava constituir uma união aduaneira e foi responsável por criar algumas instituições comunitárias, como a Corporação Andina de Fomento (CAF). Nos anos 1990, após um período de crise, o Pacto Andino foi relançado como Comunidade Andina de Nações (CAN) (Botelho, 2013; Malamud, 2003; Simões, 2010). Em 1980, a Associação Latino-Americana de Integração (Aladi) sucedeu a Alalc. Com uma estrutura mais aberta do que sua antecessora, o novo organismo tinha como objetivo criar um mercado comum por meio de uma série de iniciativas multilaterais flexíveis e diferenciadas, segundo o nível de desenvolvimento de cada país. Até hoje, a Aladi funciona como uma espécie de depositária dos acordos bilaterais ou multilaterais na América Latina.

Os experimentos de integração criados entre 1960 e 1980, conquanto não tenham sido totalmente bem-sucedidos, em função dos regimes militares e da adoção generalizada do modelo substitutivo de importações, apresentavam um forte ethos anti-hegemônico, ou, pelo menos, a aspiração de constituir um espaço político-econômico integrado na América Latina, sem a presença dos Estados Unidos (Lima, 2013). O final do período desenvolvimentista, que coincidiu com a transição de- 
mocrática, foi sucedido por uma década marcada por profunda crise econômica e social. Entretanto, foi nesse contexto tumultuado que ocorreu uma nova aproximação entre Brasil e Argentina e que acabou resultando na criação do Mercosul.

O modelo de integração bilateral, baseado no Programa de Integração e Cooperação Econômica (PICE) de 1986 e no Tratado de Integração, Cooperação e Desenvolvimento, de 1988, previa a constituição de um espaço econômico comum por meio de um programa gradual de abertura comercial e de criação de mecanismos de desenvolvimento industrial e tecnológico entre Brasil e Argentina (Guimarães, 2006; Moniz Bandeira, 2010a). No entanto, alterações profundas nos contextos nacional e internacional modificariam os rumos do processo de integração nos anos 1990.

Com a vitória de Fernando Collor e de Carlos Menem, as coalizões liberal-conservadoras adaptaram os objetivos do Tratado de 1988 às políticas de abertura econômica, visando a acelerar o ritmo da liberalização comercial. Em 1991, o Tratado de Assunção incorporou o Paraguai e o Uruguai ao eixo bilateral Brasil -Argentina, criando o Mercosul. O novo bloco abandonou os aspectos desenvolvimentistas e passou a funcionar como um esquema de redução automática de barreiras comerciais. Criouse uma zona de livre comércio e reduziram-se os prazos para a formação da união aduaneira. O Mercosul passou a funcionar como um modo de lock in, acelerando as políticas de ajuste estrutural em cada um dos sócios, em consonância com a proposta de regionalismo aberto da Cepal, que preconizava a aceitação das reformas orientadas para o mercado. Além disso, o Tratado de Assunção sequer mencionava o conceito de assimetria, limitando-se a estabelecer prazos de liberalização distintos para os países menores (Guimarães, 2006; Lima, 2013; Moniz Bandeira, 2010a).

No plano internacional, a década de 1990 foi marcada pela prevalência da iniciativa política dos Estados Unidos e pela reafirma- ção de sua posição hegemônica no continente. Com o fim da Guerra Fria e o avanço do receituário neoliberal na América Latina, os processos de integração convergiram sob a liderança norte-americana. O primeiro passo foi o acordo de livre comércio entre os Estados Unidos e o Canadá, logo estendido ao México, com a formação do Tratado de Livre Comércio da América do Norte (Nafta). Em seguida, surgiu a proposta de integração hemisférica em torno da Área de Livre Comércio das Américas (Alca), o que permitiria aos Estados Unidos não apenas expandir seu domínio sobre os mercados sul -americanos, mas também alinhar os Estados do subcontinente às suas diretrizes políticas e ao modelo liberal de democracia (Lima, 2013; Moniz Bandeira, 2010a; Pecequilo, 2013).

O processo de negociação da Alca e a adesão do México ao Nafta contribuíram decisivamente para a retomada do conceito de América do Sul, sobrepondo a geografia à ideia de latinidade. Ao retomar esse conceito, o Brasil tacitamente reconhecia que era incapaz de exercer qualquer influência significativa no conjunto da América Latina. Ademais, o conceito de América Latina seria genérico e teria perdido sentido quando a política externa mexicana renunciou a qualquer expectativa autonomista. Ao circunscrever o processo de integração à América do Sul, o Brasil resgatou um conceito essencialmente geopolítico e geoestratégico, em virtude das características econômicas, políticas e culturais que distinguem a sub-região das demais áreas (Costa, 2010; Moniz Bandeira, 2010b; Souza, 2009).

A primeira proposta concreta de formar um bloco sub-regional foi a Área de Livre Comércio Sul-Americana (Alcsa), apresentada durante o governo Itamar Franco (1992-1994), que objetivava constituir um contrapeso ao Nafta, mediante a formação de um espaço econômico sul-americano nucleado pelo Mercosul. No primeiro mandato do presidente Fernando Henrique Cardoso (1995-1998), a ideia da Alcsa foi progressivamente esquecida, abandonando-se o projeto sul-americano mais 
amplo. No entanto, as difíceis negociações da Alca e a não reciprocidade dos países desenvolvidos em relação às demandas brasileiras fizeram com que a noção de América do Sul voltasse a ser um conceito-chave no final do segundo governo Fernando Henrique (19992002). Com as reuniões presidenciais sul-americanas, a diplomacia brasileira reafirmou seu interesse em construir um espaço regional integrado. Nesses encontros, entretanto, ainda não estava presente uma visão política da América do Sul. Com o governo Lula (20032010), a região passou a ser apresentada como a maior prioridade da política externa brasileira. A visão autonomista de sua política exterior teve como objetivo fortalecer os mecanismos de cooperação regional e articular um espaço econômico e político sul-americano (Moniz Bandeira, 2010a; Santos, 2005; Simões, 2010; Vigevani; Ramanzini Júnior, 2014).

Nos anos 2000, a América Latina deixou para trás a homogeneização forçada da década anterior, quando teve de se submeter ao ajuste estrutural e às condicionalidades impostas pela crise da dívida externa. Os resultados negativos das políticas neoliberais contribuíram para reduzir a influência dos Estados Unidos na região. Os cenários homogeneizantes tiveram de ser revistos diante da crescente complexificação do subcontinente. Nesse sentido, houve um reordenamento do espaço regional $\because$ que resultou em diferentes modelos de integração, formatos de democracia e opções de política externa. A heterogeneidade das experiências nacionais levou a variações nas esferas política e econômica, sobretudo na América do Sul (Botelho, 2013; Lima, 2013).

As consequências danosas das políticas de ajuste neoliberal contribuíram para criar um ambiente favorável à vitória das oposições de centro-esquerda na América do Sul. Paralelamente às transformações no plano doméstico, o contexto internacional, marcado pelas intervenções dos Estados Unidos no Afeganistão e no Iraque, permitiu que os novos governos sul-americanos adotassem políticas exteriores autônomas. Henry Kissinger (2001) percebeu essas mudanças como uma nova forma de nacionalismo que buscaria uma identidade regional em oposição aos Estados Unidos. Esses governos representariam o principal desafio à política hemisférica norte-americana desde a Doutrina Monroe. Hodiernamente, a ameaça comunista foi substituída pelo perigo do populismo autoritário de lideranças que insistem em adotar políticas externas e formas de regionalismo mais autônomas. Isso significa que os principais formuladores da política externa dos Estados Unidos continuam considerando a região uma área estratégica e estão dispostos a impedir o surgimento de um polo alternativo de poder capaz de questionar sua hegemonia no Hemisfério Ocidental.

Antes de analisar as diferentes organizações surgidas recentemente, é preciso tecer algumas observações acerca das particularidades dos atuais processos de regionalização. Inicialmente, faz-se necessário ajustar as lentes conceituais à realidade da região e superar os modelos teleológicos de integração. A alegada experiência frustrada da integração latino -americana ou sul-americana decorre do fato de muitos especialistas adotarem o modelo idealizado e etapista europeu. No entanto, as duas regiões seguiram caminhos bastante diferentes, mostrando que as teorias orientadas para a União Europeia são insuficientes para explicar a regionalização na América do Sul. Dessa maneira, a análise dos esquemas de integração requer a necessidade de perceber as ferramentas que podem ter sido úteis para o caso europeu, mas nem por isso são adequadas à compreensão do processo que ocorre ao Sul. Assim, conhecer as especificidades é o primeiro passo para uma teorização não abstrata, mas contextualizada da integração sul-americana (Lima, 2013; Malamud, 2003; Sarti, 2011).

No esforço analítico e prático de estabelecer as bases conceituais do regionalismo sul-americano, Maria Regina Soares de Lima (2013) reconhece que o primeiro passo é arquivar o argumento teleológico do modelo eu- 
ropeu e, em seguida, propõe a distinção entre processos de integração e de regionalização. De um lado, o conceito de integração implica redução ou eliminação de restrições à livre circulação de bens, capitais, serviços e pessoas, além de envolver, em alguns casos, a delegação de soberania a uma autoridade supranacional. De outro, o regionalismo significa processos de cooperação em diversas áreas - política, econômica, energética, militar, técnica -, refletindo prioridades de política externa e destacando a dimensão geoestratégica. O regionalismo possui ainda objetivos menos ambiciosos, por ser uma dinâmica basicamente intergovernamental, envolvendo graus variados de coordenação de políticas governamentais e quase nenhuma delegação de soberania. Além dessas diferenças, Ingrid Sarti (2011) tem razão quando afirma que a integração, o regionalismo e as relações internacionais de cooperação nunca são questões meramente técnicas, pois sempre estão sujeitas às determinações das disputas de poder e condicionadas às variações políticas representadas nos governos.

De uma concepção integracionista que privilegiava a questão comercial, os governos sul-americanos passaram a dar preferência a processos mais cooperativos. O caráter apolítico dos velhos mecanismos foi substituído por uma repolitização da agenda, deslocando-se a ênfase de temas comerciais e econômicos para assuntos políticos. O novo regionalismo, como processo dinâmico e não estático, reconhece a importância do comércio, mas vai além dessa dimensão. Trata-se de um fenômeno alternativo à integração comercial tradicional, pois agrega fatores estratégicos como segurança, solução de conflitos, defesa dos direitos humanos, vigência da democracia, desenvolvimento socioeconômico integral e equitativo, proteção do meio ambiente e integração física e energética. Assim, os governos sul-americanos vêm propondo modelos de regionalismo que pretendem alterar o paradigma de integração econômica tradicional, de caráter assimétrico e insuficiente.

\section{OS DIFERENTES PROJETOS DE REGIONALISMO NA REGIÃO}

Uma das principais características do atual reordenamento do espaço regional é a heterogeneidade dos diversos regionalismos, que são marcados pela não convergência dos regimes comerciais e pela pluralidade das ideologias. Nos últimos anos, observou-se um relativo deslocamento da América do Sul, como subsistema de crescente relevância por suas políticas domésticas e externas de alto perfil, em relação às Américas do Norte e Central, que mantiveram uma relação de verticalidade com os Estados Unidos. Por um lado, há alianças mais ou menos incondicionais entre o Norte e o Sul, expressas pelos tratados de livre comércio, pelo Nafta e pela Aliança do Pacífico. Por outro, novas configurações SulSul questionam, com diferentes graus, as assimetrias econômicas e políticas do sistema internacional. Entre as organizações que adotam um regionalismo pós-liberal, destacam-se a Alba, a Comunidade dos Estados Latino-Americanos e Caribenhos (Celac) e a Unasul. Essas últimas constituem iniciativas que partem dos próprios países latino-americanos, inserindose no movimento mais geral e visando a uma ordem internacional multipolar (Ayerbe, 2014; Lima, 2013; Pecequilo, 2013; Preciado, 2008).

Com o fracasso da Alca, houve uma proliferação de acordos bilaterais de livre comércio, gerando um ambiente adverso para projetos de integração regional ou sub-regional. Muitos analistas advertem que os tratados de livre comércio reduzem a margem de manobra dos países, impedindo a adoção de políticas que poderiam ser utilizadas para seu desenvolvimento. Esses acordos abrangem temas como liberalização de investimentos, compras governamentais, desregulamentação da saúde, da educação e do mercado de trabalho, além de fortalecer os direitos de propriedade intelectual. Nos últimos anos, os Estados Unidos firmaram acordos com vários países latino-americanos, consolidando o equivalente a uma 
nova Alca e cercando o Mercosul e a CAN. No âmbito sul-americano, foram firmados acordos de livre comércio com Chile, Peru e Colômbia. Nos dois últimos casos, os tratados causaram prejuízos imediatos e irreversíveis à CAN, levando a Venezuela a deixar a organização. Em seguida, Bolívia e Equador sinalizaram que gostariam de aderir ao Mercosul, o que exigiria que ambos renunciassem previamente de sua vinculação à CAN. Além disso, os norte-americanos ameaçaram assinar um tratado de livre comércio com o Uruguai, que, caso efetivado, significaria um duro golpe para o Mercosul. Com esses acordos, os Estados Unidos procuram dificultar as iniciativas sub-regionais de integração autônoma na América do Sul (Botelho, 2013; Preciado, 2008; Sosa, 2013; Souza, 2009).

A Declaração de Lima, em 29 de abril de 2011, e o Acordo Marco de Antofagasta, em 6 de junho de 2012, deram origem à Aliança do Pacífico, que tem como fundadores Chile, Colômbia, Peru e México. As economias desses países estão entre as mais abertas da região e possuem tratados de livre comércio com os Estados Unidos. A Aliança do Pacífico adota um modelo de regionalismo liberal, que privilegia temas econômicos e comerciais. O objetivo do bloco é facilitar a convergência e a consulta mútua entre seus membros para garantir a livre circulação de todos os fatores produtivos: bens, capital, serviços e mão de obra. Ademais, pretende criar sinergias com o dinâmico mercado N . da Ásia-Pacífico. Todavia observa-se uma bai罂 xa complementariedade econômica entre seus

\% da em produtos primários, o que pode comproTry meter as ambições do novo organismo. Assim, \& pode-se dizer que a Aliança do Pacífico tem ờ mais importância ideológica do que econômica

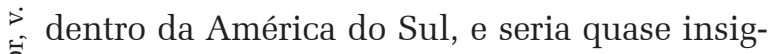
nificante politicamente se não integrasse uma pequena parcela do projeto norte-americano de criar a Trans-Pacific Partnership (TPP) ou Parceria Transpacífica. ${ }^{3}$ (Fiori, 2014; Muñoz, 2012).

${ }^{3}$ A TPP é um processo plurilateral que envolve diversos países, de diferentes continentes, representando um
Apesar de suas bases econômicas, alguns analistas consideram que a Aliança do Pacífico esconde interesses geopolíticos e possui a intenção de fazer frente ao regionalismo pós-liberal. O bloco seria, ao mesmo tempo, uma ponte para o Nafta e um contraponto à Alba, ao Mercosul e ao Brasil. Entre as repercussões geopolíticas da Aliança do Pacífico, destacam-se o reforço da presença estadunidense na América do Sul através do México e a diminuição do protagonismo de Brasil e Venezuela. Adicionalmente, o acordo poderia servir de instrumento para apoiar aliados norte-americanos como Chile e Colômbia. Setores do establishment estadunidense consideram a Aliança do Pacífico mais pragmática e menos ideológica do que a ameaça bolivariana representada pela Alba. Em relação ao Mercosul, a presença de Paraguai e Uruguai entre os membros observadores da organização indica seu potencial de clivagem e fragmentação. Assim, vislumbra-se uma tendência à bifurcação da América Latina em dois eixos: o do Pacífico, que retoma a agenda de livre comércio e adota políticas externas alinhadas aos Estados Unidos, e o do Atlântico, com modelos econômicos mais intervencionistas e políticas exteriores autônomas (Ayerbe, 2014; Lima, 2013; Muñoz, 2012; Vigevani; Ramanzini Júnior, 2014).

A Alba é uma iniciativa do ex-presidente venezuelano Hugo Chávez e foi lançada em contraposição à Alca, em 2004. Pertencem à organização Antígua e Barbuda, Bolívia, Cuba, Dominica, Equador, Nicarágua, São Vicente e Granadinas e Venezuela. A Alba tem caráter prioritariamente político e propõe desenvolver uma integração solidária, buscando o bem-estar dos povos e a defesa do comércio justo e do desenvolvimento sustentável. A identidade da organização baseia-se na afinidade ideológica entre seus membros. Ao estruturar um eixo po-

dos maiores acordos comerciais do mundo. Devido à sua abrangência, alguns críticos temem que os Estados Unidos utilizem o acordo para impor sua regulação sobre propriedade intelectual aos demais parceiros. Além disso, a TPP permite que empresas norte-americanas possam processar diretamente os governos que cometam qualquer infração ao acordo 
lítico-ideológico, a Alba representa um projeto claramente anti-hegemônico e anti-imperialista. Trata-se de uma proposta conflitante com a Aliança do Pacífico, mas que é transversal à Unasul. De fato, a Alba pode existir paralelamente à Unasul, pois cumpre funções diferentes e, ao mesmo tempo, complementares. Ao servir de plataforma para o protagonismo venezuelano, permite à Unasul seguir com seu ritmo gradual e sua busca pelo consenso na região (Botelho, 2013; Carrión Mena, 2013; Preciado, 2008; Saraiva, 2010).

Em 2011, a criação da Celac constituiu um passo importante na busca de uma maior integração da região para enfrentar problemas comuns. O objetivo é servir como espaço de consulta e concerto político da América Latina, estabelecendo uma interlocução mais equilibrada com os Estados Unidos. A organização é resultado da convergência gradual entre o Grupo do $\mathrm{Rio}^{4}$ e a Cúpula América Latina-Caribe. Alguns analistas consideram que o novo organismo poderia eventualmente substituir a OEA, enquanto outros acham que a OEA continuará sendo importante para tratar de temas que envolvam todos os países das Américas, incluindo Canadá e Estados Unidos, ausentes da Celac. Assim, a formação da Celac, que contou com decisivo apoio brasileiro e venezuelano, é uma tentativa de ampliar os limites da cooperação regional para além da América do Sul, contribuindo para recriar a ideia de América Latina em um contexto de crescente heterogeneidade (Borda, 2012; Lima, 2013; Simões, 2010; Sosa, 2013).

A Unasul tem um perfil diferente das outras iniciativas e se aproxima mais de um instrumento de governança regional do que dos padrões clássicos de integração. A organização percorreu o caminho inverso ao de blocos que somente adquiriram uma dimensão

${ }^{4}$ O Grupo do Rio foi criado em 1986, como mecanismo permanente de consulta e concertação política na América Latina e no Caribe. O fórum surgiu a partir da fusão entre o Grupo de Contadora (Colômbia, México, Panamá e Venezuela) e o Grupo de Apoio à Contadora (Argentina, Brasil, Peru e Uruguai), que buscavam uma solução negociada e pacífica para a crise centro-americana dos anos 1980 (Saraiva, 2010). política após consolidarem a comercial. Tratase de um espaço multilateral de coordenação e cooperação política interestatal que difere dos esquemas de integração convencionais. Nesse sentido, representa a vertente política do novo regionalismo, que absorve demandas econômicas, mas que ultrapassa essa esfera. Por não ser um regime comercial, a Unasul não compete nem pretende substituir nenhum dos regimes existentes, mas permite que os diferentes países possam cooperar em diversos campos: energético, militar, social, logístico e de infraestrutura. Dessa forma, a Unasul atua como mecanismo de construção de consensos, acomodando distintas visões sobre integração (Borda, 2012; Lima, 2013; Meunier; Medeiros, 2013; Nafalski, 2011; Saraiva, 2010).

No interior da Unasul, coexistem a Alba, o Mercosul e a Aliança do Pacífico. Enquanto os agrupamentos bolivariano e Atlântico são partidários de um projeto de desenvolvimento crítico ao liberalismo e mais voltado para a integração endógena sul-americana, o eixo do Pacífico possui uma nítida coloração neoliberal e está mais orientado ao mercado mundial. Essa diversidade é parte integrante do contexto heterogêneo no qual foi criada a Unasul. A fim de acomodar a pluralidade ideológica do subcontinente, o discurso da Unasul não recorre ao enfoque anti-hegemônico da Alba, nem à complacência da Aliança do Pacífico, mas enfatiza a autonomia política regional e a necessidade de projetar geopoliticamente a América do Sul. Nesse sentido, o convívio entre diferentes visões da integração, que, em muitos casos, se sobrepõem, ressalta a importância de se pensar na possibilidade de múltiplos níveis de regionalismo. Ademais, deve-se destacar que a política externa brasileira tem atuado com vistas a construir o consenso entre as nações vizinhas, procurando superar crises regionais e buscando ocupar um papel central no âmbito da Unasul. 


\section{UNASUL: a construção de um proje- to político sul-americano}

A Unasul representa uma tentativa inédita de articulação política de todos os países da América do Sul. A ênfase na dimensão política está relacionada com a necessidade de afirmação da autonomia, objetivo presente em diversos momentos históricos dos países sul-americanos. A criação da Unasul constitui um dos fatos mais importantes na história do processo de integração regional. No passado, houve tentativas de cooperação ou integração nos planos pan-americano, hispano-americano, latino-americano e sub-regional. Todavia, antes da Unasul, os países da região nunca tinham assinado um tratado ou instrumento jurídico de caráter tão amplo, envolvendo os doze países da América do Sul.

Com os encontros presidenciais sul-americanos, inaugurou-se um espaço político de diálogo autônomo e específico, envolvendo, além do Mercosul e da CAN, o Chile, a Guiana e o Suriname. Se o discurso empresarial costumava salientar um Chile desenvolvido, diferente da região, e modelo para ela, sua inserção na Comunidade Sul-Americana de Nações (CSN) e, posteriormente, na Unasul, abriu novas possibilidades de relacionamento e de construção identitária para o país andino. Para a Guiana e o Suriname, que eram membros da - Comunidade do Caribe (Cariom) e haviam ficado de fora da Alcsa, o ingresso na Unasul ณ envolvimento político e econômico com os deஜ mais países da América do Sul (Meunier; Meक्ञ⿰冫⿰亅⿱丿丶丶 deiros, 2013).

Na I Reunião de Presidentes da América do Sul, em 2000, discutiu-se como organizar a convivência cooperativa e coordenada entre os Estados nos setores de comércio, infraestrutura, luta contra drogas ilícitas, informação e tecnologia. Apesar de não definir os objetivos políticos, o propósito econômico do encontro estava claro: criar uma área de livre comércio entre Mercosul e CAN. No entanto, a decisão mais importante foi a criação da Iniciativa para a Integração da Infraestrutura Regional Sul-Americana (IIRSA), ${ }^{5}$ visando à integração física do subcontinente. Em 2002, a II Reunião de Presidentes da América do Sul conferiu especial atenção à IIRSA e tratou a Alca de forma sucinta e sem manifestação de apoio (Botelho, 2013; Costa, 2010; Meunier; Medeiros, 2013; Rocha Valencia; Morales Ruvalcaba, 2013).

Em dezembro de 2004, foi realizada, na cidade de Cusco, a III Reunião de Presidentes da América do Sul, ocasião em que foi redigida a Declaração de Cusco, que lançou a CSN, base da futura Unasul. A Declaração de Cusco invoca os líderes da independência sul-americana - Bolívar, Sucre e San Martín - e faz referência à história e aos desafios comuns dos países da região. Há ainda menção a uma identidade sul-americana compartilhada, sustentada por valores comuns. A Declaração de Cusco aponta para a superação do âmbito comercial, ao estabelecer, entre os objetivos do novo bloco, a concertação política e diplomática. Ao longo do texto, mais de uma vez, o primeiro item destacado é o político, revelando que o objetivo da CSN não é apenas econômico, mas estratégico. Ademais, o documento destaca que o desenvolvimento econômico deve passar pelo reconhecimento das assimetrias regionais e pela coesão e inclusão social (Botelho, 2013; Nafalski, 2011; Vigevani; Ramanzini Júnior, 2014).

A CSN consolidou-se em torno de três ideias centrais: a concertação e coordenação de políticas exteriores; a convergência entre Mercosul, CAN, Chile, Guiana e Suriname; e a integração física através da IIRSA. Entre 2005 e 2007, foram celebradas três cúpulas essenciais na definição dos contornos institucionais e dos objetivos do que se converteria em Unasul. Em 2005, a I Cúpula da CSN, realizada em Brasília, 5 A IIRSA tem como principal objetivo promover a
integração física nas áreas de transporte, comunicações
e energia. Inicialmente, a iniciativa foi influenciada por
instituições financeiras multilaterais como o BID e a CAF.
A maioria dos projetos de infraestrutura visava à criação
e expansão de corredores de exportação de produtos de
baixo valor agregado. Com sua incorporação à Unasul, os
governos procuraram aumentar sua participação e agregar
uma visão política à iniciativa 
apresentou as primeiras ideias sobre a institucionalidade do novo organismo. Na II Cúpula da CSN, realizada em Cochabamba no final de 2006, foram definidos os princípios e os objetivos do novo modelo de integração. A Declaração de Cochabamba ressalta que a construção da CSN deve envolver os âmbitos político, social, cultural, econômico, financeiro, ambiental e de infraestrutura. Além de ser vista como necessária para enfrentar os problemas sociais que afetam a região, a integração sul-americana é percebida como um passo decisivo para alcançar um mundo multipolar. A declaração destaca que a integração almejada deve ter uma identidade própria, pluralista, reconhecendo as distintas concepções políticas de cada país. Isso garantiu a participação de governos com posições ideológicas tão díspares como o colombiano e o venezuelano. O documento menciona que uma das premissas para a integração é a valorização da identidade sul-americana. Entre os objetivos da CSN, destacam-se a superação das assimetrias, a infraestrutura, a formação de uma cidadania sul-americana e a participação cidadã (Borda, 2012; Botelho, 2013; Nafalski, 2011; Rocha Valencia; Morales Ruvalcaba, 2013).

O terceiro e último encontro antes da criação da Unasul ocorreu com a I Cúpula Energética Sul-Americana, realizada em Isla Margarita, na Venezuela, em abril de 2007. No encontro, os chefes de Estado decidiram que a CSN ou Casa passaria a se chamar Unasul. Essa mudança não foi uma simples troca de nome ou sucessão, pois significou a transformação de um fórum de concertação política em uma organização internacional. ${ }^{6}$ Ademais, foram tomadas outras medidas relevantes, como a instituição de uma Secretaria Geral com sede em Quito e a criação do Conselho Energético Sul-Americano (CES), que se tornou o primeiro conselho temático da nascente

${ }^{6}$ Celso Amorim (2013) chama a atenção para uma pequena discussão sobre o nome do novo organismo, na qual acabou predominando a visão de Hugo Chávez, Unasul, em detrimento da proposta brasileira, Comunidade ou Casa. Apesar de a ideia brasileira ser, em princípio, mais aberta ou plural, a palavra Unasul possui uma conotação geopolítica e estratégica.. instituição. Assim, ao longo das três reuniões ocorridas entre 2005 e 2007, foram estabelecidas as diretrizes centrais que possibilitaram a criação da Unasul (Botelho, 2013; Costa, 2010; Rocha Valencia; Morales Ruvalcaba, 2013).

No dia 23 de maio de 2008, foi celebrada, em Brasília, uma reunião extraordinária entre os líderes sul-americanos, que resultou no Tratado Constitutivo da Unasul, que entraria em vigor no dia 11 de março de 2011, após alcançar o número necessário de ratificações. O preâmbulo do tratado faz referência à história compartilhada, aos líderes da independência e à construção de um futuro comum. O texto está inspirado pelas Declarações de Cusco, Brasília e Cochabamba, e destaca a determinação dos países signatários de construir uma identidade e uma cidadania sul-americanas e desenvolver um espaço regional integrado nas esferas política, econômica, social, ambiental, energética e de infraestrutura. Reafirma-se o compromisso de combater a exclusão e as desigualdades sociais e de reduzir as assimetrias. Além disso, o tratado possui um claro viés geopolítico, ao enfatizar que a integração é um passo decisivo para fortalecer o multilateralismo e construir um mundo multipolar (Botelho, 2013; Unasul, 2008). Desse modo, o cerne do novo bloco encontra-se na dimensão política e no seu intuito de afirmar a região como um polo essencial do sistema internacional.

Entre os objetivos gerais, previstos no artigo $2^{\circ}$ do tratado, destacam-se o diálogo político, as políticas sociais, o meio ambiente, a energia, a infraestrutura e o financiamento, deixando de lado o componente comercial. O artigo $3^{\circ}$ elenca os vinte e um objetivos específicos, que inclui itens que já vinham sendo mencionados desde as primeiras cúpulas presidenciais no início dos anos 2000. O conjunto desses objetivos constitui um discurso que se materializa em um documento de intenções e de direcionamento da integração regional, mas que não forma propriamente uma agenda. Um olhar atento ao texto do tratado permite concluir que não há nenhuma cláusula específica 
sobre questões comerciais, nem alusão às modalidades habituais de integração de mercados - zona de livre comércio ou união aduaneira. Assim, a Unasul foi constituída como uma organização política guarda-chuva, pois abriga, em sua institucionalidade, uma série de ações que, somadas, apontam para uma articulação política mínima entre todos os países da América do Sul (Borda, 2012; Botelho, 2013; Costa, 2010; Unasul, 2008).

Ao analisar os textos das declarações da CSN e do tratado constitutivo da Unasul, é possível constatar a presença de uma recorrente terminologia identitária. Segundo Isabel Meunier e Marcelo de Almeida Medeiros (2013), a remissão a símbolos históricos sugere a intenção de revestir instrumentos formais de elementos emocionais, o que indica a busca de uma fundamentação para o projeto integracionista desvinculada de cálculos utilitários. Nesse sentido, a amplitude dos objetivos da instituição reforça o desejo de superar a mera integração econômica. Além disso, os autores observam que o argumento identitário se coloca como instrumento para construir um elo entre passado, presente e futuro, uma espécie de ponte que se materializaria na Unasul.

A estrutura institucional da Unasul está prevista no artigo $4^{\circ}$ do Tratado Constitutivo e é formada pelos seguintes órgãos: Conselho de Chefas e Chefes de Estado e de Governo, Conselho de Ministras e Ministros das Relações iิ Exteriores, Conselho de Delegadas e Delegados 象 e a Secretaria Geral. Essa estrutura institucio¿ nal conta também com doze conselhos temáti\& cos cuja finalidade é auxiliar e propor políticas 될 públicas para o bloco a partir de suas respec\& tivas áreas. Os conselhos são integrados por oิ ministros vinculados aos respectivos temas e contam com órgãos de assessoramento e estudos, com sede e funcionários próprios, além de grupos de trabalho. Ao estabelecer um arcabouço institucional para ampliar a cooperação regional em diferentes políticas públicas, os conselhos estimulam a participação de diversos atores políticos e econômicos no âmbito de cada país, muitos comprometidos com a regionalização em suas múltiplas facetas (Botelho, 2013; Lima, 2013; Unasul, 2008).

Depois de absorver o CES, criado em 2007, a Unasul criou outros onze conselhos entre 2008 e 2012. Na reunião extraordinária de chefes de Estado ocorrida em Salvador, em 2008, foram criados o Conselho Sul-Americano de Defesa (CDS) e o Conselho de Saúde Sul -Americano (CSS). Ambos contam com uma instância de assessoramento e estudos: o Centro de Estudos Estratégicos de Defesa (CEED), com sede em Buenos Aires, e o Instituto Sul -Americano de Governo em Saúde (ISAGS), sediado no Rio de Janeiro. Na cúpula de Quito, em 2009, surgiram mais três conselhos: problema mundial das drogas (CSPMD); desenvolvimento social (CSDS); e de infraestrutura e planejamento (COSIPLAN). A partir de 2010, a IIRSA foi incorporada ao Cosiplan e tornouse um órgão técnico do conselho, passando a receber diretrizes políticas dos governos pertencentes à Unasul. Nos anos seguintes, foram criados outros conselhos nas seguintes esferas: educação (CSE); cultura (CSC); ciência, tecnologia e inovação (COSUCTI); economia e finanças (CSEF); segurança cidadã contra a delinquência organizada transnacional (DOT); e eleitoral (CEU). O Conselho Eleitoral da Unasul, responsável pela organização de missões e pelo intercâmbio de conhecimento na área eleitoral, teve como primeira missão acompanhar o processo eleitoral venezuelano de 2012. (Botelho, 2013; Costa, 2010; Vigevani; Ramanzini Júnior, 2014). Na Figura 1, observa-se o esquema político-institucional geral da Unasul.

A criação da Unasul representou uma mudança nas concepções de Brasil e Venezuela sobre o alcance temático e territorial da integração. Os incentivos econômicos não são suficientes para explicar o surgimento da Unasul e precisam ser combinados com os objetivos políticos dos governos. No caso brasileiro, a ideia de superar a dimensão comercial foi fortalecida com a chegada de Lula ao poder. Além da atuação do presidente, a política externa 
Figura 1 - Estrutura organizacional da Unasul

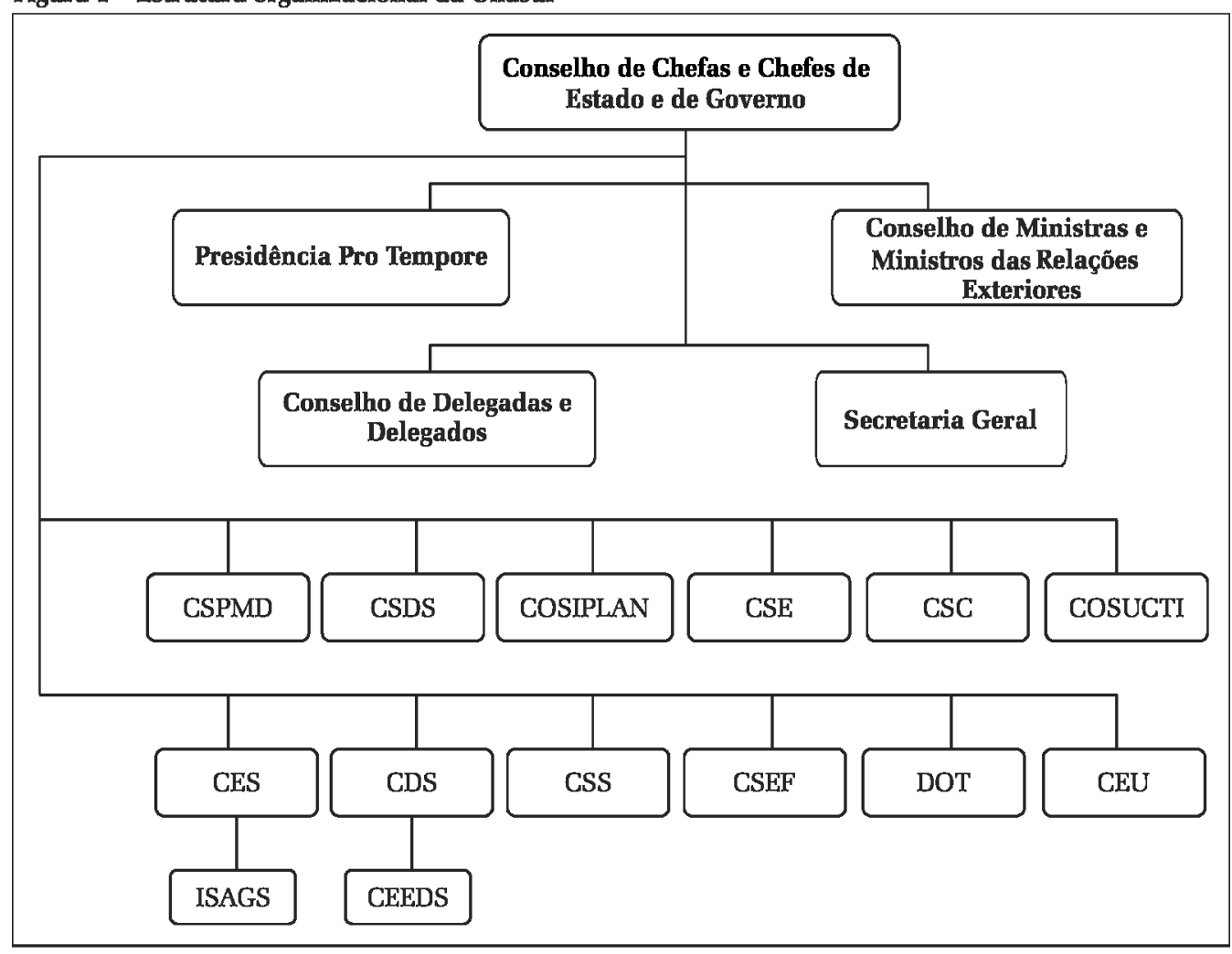

Fontes: Elaborado pelo Autor (2015).

brasileira contou com formuladores importantes como o Ministro Celso Amorim, o embaixador Samuel Pinheiro Guimarães e o assessor Marco Aurélio Garcia. Enquanto Amorim sempre reiterou a dimensão econômica como ponto fundamental para alcançar a unidade política, Guimarães e Garcia apostaram em um processo político que pudesse resultar em ganhos de autonomia, econômicos e sociais para a região. No caso venezuelano, a ascensão de Hugo Chávez trouxe mudanças à política externa do país, que passou a incorporar uma visão geopolítica e a priorizar a integração regional, enfatizando sua dimensão política. Assim, o principal fator para o surgimento da Unasul foi a atuação dos governos Lula e Chávez, que lograram superar obstáculos históricos à integração e aproveitar o contexto regional e internacional favorável ao avanço do processo (Botelho, 2013; Costa, 2010).

O Brasil e a Venezuela coincidem sobre a necessidade de um perfil político para o novo regionalismo, que deve ser um instrumento para políticas de desenvolvimento distributivas e contribuir para a projeção internacional sul-americana. No entanto, ambos divergem sobre os meios para alcançar tal desiderato. Os contrastes são demarcados pelas estratégias de cada país. Por um lado, a estratégia venezuelana baseia-se em uma visão geoestratégica e militar marcada pela retórica inflamada de Chávez e Maduro. A política externa venezuelana caracteriza-se pelo caráter confrontacional e antagônico em relação aos Estados Unidos. Ademais, sua concepção da Unasul é a de uma organização que se aproxima do ideário bolivariano. Por outro, a estratégia brasileira é multidimensional e se apoia no desenvolvimento comercial e produtivo. A moderação da diplomacia brasileira é explicada pela aspiração do país em converter-se em um ator de referência global a partir da afirmação de sua liderança na região. Por isso, o Brasil busca uma convivência harmônica com os Estados Unidos e não concebe a Unasul como um organismo anti-imperialista. Apesar das diferenças, as duas estratégias pos- 
suem uma visão multipolar do mundo (Borda, 2012; Botelho, 2013; Serbin 2011).

As divergências entre os países da Unasul envolvem também questões relativas à concepção de determinados órgãos e à relação entre o organismo e outras instituições. A criação do CDS envolveu um amplo debate entre os líderes. Inicialmente, Chávez havia proposto uma institucionalidade de segurança coletiva, dotada de orçamento próprio, uma espécie de aliança político-militar. Essa sugestão foi habilmente substituída pela proposta brasileira de criar um conselho no âmbito da Unasul, cujo objetivo seria incentivar a prevenção e a resolução de conflitos. Em realidade, o CDS deveria funcionar como um fórum para promover o diálogo e a cooperação entre os Ministérios da Defesa de cada país. O ineditismo geopolítico do CDS resulta do fato de ser um arranjo de defesa exclusivamente sul-americano, rompendo com o histórico de instituições hemisféricas tuteladas pelos Estados Unidos. Ao se estabelecer como instância permanente da Unasul, o CDS representa a apropriação, pela região, dos problemas relativos à defesa, antes tratados de maneira descoordenada e com envolvimento de potências externas (Costa, 2010; Lima, 2013; Serbin, 2011; Simões, 2010).

A tensão com outras organizações internacionais é mais explícita em relação à OEA, cuja agenda política é similar à da Unasul. Al๑ guns especialistas acreditam que a criação de instituições regionais próprias representa uma 象 reação crítica a entidades tradicionais como a essa percepção não é compartilhada por todos os países da região. No caso do México, a proximidade geográfica e a interdependência econômica fazem da OEA um espaço multilateral importante em sua relação com os Estados Unidos. Há também divergências no âmbito da Unasul. Enquanto alguns membros veem o novo organismo como um entre múltiplos tabuleiros, como a Colômbia, outros simplesmente o enxergam como um foro que poderá contribuir para debilitar a OEA, a exemplo de Equador e Venezuela (Borda, 2012; Lima, 2013; Muñoz, 2012).

A melhor maneira de verificar se houve perda de influência por parte da OEA é analisar a intervenção da Unasul em algumas crises regionais. A crise boliviana de 2008, por exemplo, confirmou a crescente autonomia dos países sul-americanos na resolução de seus conflitos. A crise começou quando os departamentos bolivianos mais ricos se insurgiram contra medidas do governo Evo Morales que modificavam a repartição dos impostos sobre petróleo e gás. Os líderes sul-americanos reuniram-se em Santiago do Chile para tratar do assunto e emitiram a Declaração de la Moneda, na qual manifestaram apoio ao colega boliviano, rechaçaram os atos violentos e advertiram que não reconheceriam um governo originado de um golpe de Estado ou ação separatista. Em 2010, a Unasul reagiu energicamente à tentativa golpista contra o governo de Rafael Correa, resultando na elaboração de uma cláusula democrática sob a forma de um Protocolo Adicional ao Tratado Constitutivo da organização. ${ }^{7}$ Em 2012, a deposição do presidente paraguaio Fernando Lugo levou, pela primeira vez, à aplicação da cláusula democrática e à consequente suspensão do Paraguai do bloco (Borda, 2012; Botelho, 2013; Rocha Valencia; Morales Ruvalcaba, 2013; Serbin, 2011). O conjunto dessas atuações da Unasul revelou o progressivo enfraquecimento da OEA como organismo encarregado de contribuir para a solução pacífica e a mediação das crises regionais envolvendo os países sul-americanos.

A América do Sul não é um espaço uni-

${ }^{7}$ A cláusula democrática da Unasul possui duas características que a tornam mais legítima do que a Carta Democrática interamericana da OEA. Em primeiro lugar, sua aplicação não levanta a suspeita de estar sendo usada como justificativa para a intervenção, como fizeram os Estados Unidos muitas vezes ao longo da história. Em segundo, o compromisso da OEA é exclusivamente com a democracia representativa, enquanto a cláusula da Unasul evita o uso desse adjetivo (Borda, 2012). 
forme, pois sempre se caracterizou como uma região heterogênea, diversa e desigual que, apesar de afinidades históricas, nunca se constituiu em um bloco com interesses similares. Segundo Lima (2013), a lente conceitual para uma adequada análise do novo regionalismo sul-americano deve ser a da diversidade e da heterogeneidade e não a da fragmentação. Diferentemente do Mercosul, a Unasul surgiu em um contexto de diversidades regionais. Em seu interior, coexistem países que contam com diferentes propostas de integração econômica e orientações ideológicas distintas. Ademais, a estrutura institucional da organização tem servido de ponte entre o discurso sul-americanista comum e os vários discursos baseados nos interesses nacionais.

\section{CONSIDERAÇÕES FINAIS}

Desde que foi criada, a Unasul tem se consolidado como uma instância para a negociação de crises regionais. Trata-se de um fórum de coordenação que representa a vertente política e a principal expressão do novo regionalismo sul-americano. Sem desconhecer as diferenças entre seus membros, a instituição tem trabalhado para superá-las, mantendo um espaço permanente de interlocução. A Unasul representa o coroamento de um processo de afirmação de uma identidade sul-americana possível contra a pulverização histórica das nações da região. A organização, portanto, vem exercendo um importante papel geopolítico e geoeconômico, porquanto tem garantido maior autonomia regional e contribuído para a formação de um polo sul-americano.

Com o fim do mandato de Lula e a morte de Chávez, alguns analistas questionam se a Unasul sobreviveria a uma mudança na conjuntura política regional, após o ciclo de governos progressistas. Dilma e Maduro não possuem o carisma de seus antecessores e assumiram seus mandatos em um momento de turbulência internacional, agravada pela que- da de preços das commodities, e de crise política e econômica doméstica. Sem dúvida, o atual contexto acentua os desafios que deverão ser enfrentados pelos mandatários sul-americanos para a consolidação da Unasul.

Apesar de certos críticos não estarem convencidos de sua viabilidade e eficácia, a Unasul vem abrindo espaços, resistindo a ceticismos e superando obstáculos. Em que pese certas debilidades, a organização tem contribuído para uma maior autonomização da região no sistema mundial. Sem dúvida, sua existência não é vista com simpatia pelos Estados Unidos, pois a Unasul é uma tentativa de materializar um polo sul-americano sempre temido e evitado pela política externa norte -americana. Além disso, o sucesso da Unasul precisa ser medido por uma visão estratégica de longo prazo e não pela fotografia imediata.

Certa vez, um dos pensadores latino-americanos mais originais, o peruano José Carlos Mariátegui (2005, p.120), escreveu: "Não queremos, certamente, que o socialismo na América seja decalque e cópia. Deve ser criação heroica. Temos de dar vida, com nossa própria realidade, na nossa própria linguagem, ao socialismo indo-americano. Eis uma missão digna de uma geração nova”. A América Latina já deu mostras de originalidade com a Cepal, a teoria da dependência e a teologia da libertação. No momento, um dos principais desafios dos intelectuais e dos povos da região é aprofundar a reflexão sobre o novo regionalismo.

Recebido para publicação em 15 de outubro de 2015 Aprovado em 21 de novembro de 2015

\section{REFERÊNCIAS}

AMORIM, C. Breves narrativas diplomáticas. São Paulo: Benvirá, 2013. 168 p.

AYERBE, L. F. O regionalismo latino-americano e a política hemisférica dos Estados Unidos. Política Externa, v. 22, n. 4, p. 97-108, abr. mai. jun. 2014.

BETHELL, L. Brazil and Latin America. Journal of Latin American Studies, v. 42, p. 457-85, 2010. 
BORDA, S. Desafíos y oportunidades de la Unión de Naciones Suramericanas - UNASUR. Buenos Aires: Coordinadora Regional de Investigaciones Económicas y Sociales (CRIES), 2012. 28p. Disponível em: <http://www. cries.org/wp-content/uploads/2013/07/DOC18-web.pdf $>$. Acesso em: 15 mar. 2013.

BOTELHO, J. C. A. La creación y la evolución de Unasur. Curitiba: Juruá, 2013. 250 p.

CARRIÓN MENA, F. Unasur: ¿simple retórica o regionalismo efectivo? Fortalezas y debilidades. Quito: Friedrich Ebert Stiftung, 2013. 13 p.

COSTA, R. S. A América do Sul vista do Brasil: a estratégia de integração do governo Lula. 2010. $249 \mathrm{f}$. Tese (Doutorado em Ciência Política) - Instituto de Filosofia e Ciências Humanas, Universidade Federal do Rio Grande do Sul, Porto Alegre, 2010.

FIORI, J. L. História, estratégia e desenvolvimento: para uma geopolítica do capitalismo. São Paulo: Boitempo, 2014. 277 p.

FURTADO, C. A economia latino-americana: formação histórica e problemas contemporâneos. 4. ed. São Paulo: Companhia das Letras, 2007. 494 p.

GUIMARÃES, S. P. Desafios brasileiros na era dos gigantes. Rio de Janeiro: Contraponto, 2006. 455 p.

JAGUARIBE, H. A denúncia João Neves. Cadernos de Nosso Tempo, Rio de Janeiro, v. 2. p. 83-100, 1954.

KISSINGER, H. Does America need a foreign policy?: toward a diplomacy for the 21st century. New York: Simon \& Schuster, 2001. 318 p.

LAFER, C. A identidade internacional do Brasil e a política externa brasileira: passado, presente e futuro. 2. ed. São Paulo: Perspectiva, 2004. 151 p.

LIMA, M. R. S. Relações interamericanas: a nova agenda sul-americana e o Brasil. Lua Nova, São Paulo, 90, p. 167201,2013

MALAMUD, A. Integração regional na América Latina: teorias e instituições comparadas. In: ESTEVES, P. L. (Org.). Instituições internacionais: comércio, segurança e integração. Belo Horizonte: PUC Minas, 2003. p. 325-50.

MARIÁTEGUI, J. C. Por um socialismo indo-americano: ensaios escolhidos. Rio de Janeiro: Ed. UFRJ, 2005. 270 p.

MÁRQUEZ, G. G. O general em seu labirinto. 12. ed. Rio de Janeiro: Record, 2014. 285 p.

MEUNIER, I.; MEDEIROS, M. A. Construindo a América $\checkmark$ do Sul: identidades e interesses na formação discursiva da Unasul. DADOS - Revista de Ciências Sociais, Rio de จे Janeiro, v. 56, n. 3, p. 673-712, jul./set. 2013.

is MONIZ BANDEIRA, L. A. Brasil, Argentina e Estados is Unidos: conflito e integração na América do Sul (da ¿2 Tríplice Aliança ao Mercosul). 3. ed. Rio de Janeiro: 2. Civilização Brasileira, 2010a. 669 p

. Geopolítica e política exterior: Estados Unidos, Brasil e América do Sul. 2. ed. Brasília: FUNAG, 2010b. मे $124 \mathrm{p}$.
MUÑOZ, A. S. El nuevo mapa político y económico de América Latina: Alianza Pacífico versus UNASUR. Estúdios geográficos, [S.l.], v. 73, n. 273, p. 703-719, 2012.

NAFALSKI, G. N. Unasul: uma perspectiva de integração política sul-americana. São Paulo: Ed. Alfa-Omega, 2011. $133 \mathrm{p}$.

PECEQUILO, C. S. A América do Sul como espaço geopolítico e geoeconômico: o Brasil, os Estados Unidos e a China. Carta Internacional, São Paulo, v. 8, n. 2, p. 100115, jul./dez. 2013.

PRECIADO, J. América Latina no sistema-mundo: questionamentos e alianças centro-periferia. Caderno CRH, Salvador, v. 21, n. 53, 253-267, maio/ago. 2008.

RIBEIRO, D. O povo brasileiro: evolução e o sentido do Brasil. São Paulo: Companhia das Letras, 1995. 476 p.

ROCHA VALENCIA, A.; MORALES RUVALCABA, D. E. Desafíos en la construcción de la Unión de Naciones de Suramérica. In: GADELHA, R.M.A.F. (Org.). Mercosul a Unasul - avanços do processo de integração. São Paulo: EDUC, 2013. p. 69-117.

SANTOS, L. C. V. G. A América do Sul no discurso diplomático brasileiro. Revista Brasileira de Política Internacional, Brasília, v. 48, n. 2, p. 185-204, jul./dez. 2005.

SARAIVA, M. G. Integração regional na América do Sul: processos em aberto. Análise de Conjuntura OPSA, n. 7, p. 1-16, jul. 2010. Disponível em: <http:// observatorio.iesp.uerj.br/index.php?option $=$ com content\&view $=$ article\&id $=13 \&$ Itemid $=13>$. Acesso em: 30 jan. 2015.

SARTI, I. A arquitetura política e os desafios da institucionalidade na integracão sul-americana. In: CERQUEIRA-FILHO, G. (Org.). Sulamérica: comunidade imaginada, emancipação e integração. Niterói: Ed. UFF, 2011. p. 177-191.

SERBIN, A. Unasur frente a las crisis regionales: multipolaridad, liderazgos e instituciones regionales. In: VADELL, J. A.; CAMPOS, T. L. C. (Orgs.). Os novos rumos do regionalismo e as alternativas políticas na América do Sul. Belo Horizonte: Ed. PUC-Minas, 2011. p. 326-351.

SIMÕES, A. J. F. Integração: sonho e realidade na América do Sul. Brasília: FUNAG, 2010. 116 p.

SOSA, A. J. ¿Mercosur frente a la Unasur? In: GADELHA, R.M.A.F. (Org.). Mercosul a Unasul - avanços do processo de integração. São Paulo: EDUC, 2013. p. 119-149.

SOUZA, A. A agenda internacional do Brasil: a política externa brasileira de FHC a Lula. Rio de Janeiro: Elsevier, 2009. $191 \mathrm{p}$

UNASUL. Tratado constitutivo da União de Nações Sulamericanas. Brasília: [s.n.], 2008. 15 p. Disponível em: <http://www.isags-unasur.org/uploads/biblioteca/1/ bb[158]ling[1]anx[402].pdf > . Acesso em: 30 jan. 2015.

VIGEVANI, T.; RAMANZINI JÚNIOR, H. Autonomia, integração regional e política externa brasileira: Mercosul e Unasul. DADOS - Revista de Ciências Sociais, Rio de Janeiro, v. 57, n. 2, p. 517-552, abr./jun. 2014. 


\section{UNASUL: the political dimension of the new South American regionalism}

Tiago Nery

During the first decade of the 21st century, the rise of progressive strengths enabled the adoption of more autonomous external policies by South American countries. The neoliberal hegemony and the homogenous models of integration of the 1990s were replaced by heterogeneous types of regionalism. Among the new organizations, the Unasul is a forum for political coordination that involves cooperation in different areas. It is the political front of the new South American regionalism. Inside it there are governments with different ideological signs that participate in different integrative mechanisms. The Unasul represents the crowning of the process of statement of a possible South American identity, against the historical pulverization of the region. The new organism can become a regional minimum common denominator. Besides that, the Unasul projects South America geopolitically and contributes for the construction of a new pole in the international system.

KEYwords: Unasul. Brazilian external politics. Regionalism. International relations. South America.
UNASUR: la dimension politique du nouveau régionalisme sud-américain

Tiago Nery

Au cours de la première décennie du XXIe siècle, la montée des forces progressistes a permis aux pays d'Amérique du Sud d'adopter des politiques étrangères plus autonomes. L’hégémonie néo-libérale et les modèles homogènes d'intégration des années 1990 ont été suivis par des types de régionalisme hétérogènes. Au sein de ces nouvelles organisations, l'UNASUR joue le rôle d'un forum de coordination politique qui implique une coopération dans différents domaines. Il s'agit du volet politique d'un nouveau régionalisme sud-américain à l'intérieur duquel se retrouvent des gouvernements ayant des idéologies différentes mais qui prennent part à divers mécanismes d'intégration. L'UNASUR est l'aboutissement d'un processus d'affirmation d'une identité sud-américaine possible, en opposition à la désagrégation historique de la région. Ce nouvel organisme peut se transformer en un dénominateur commun régional. En outre, l'UNASUR permet à l'Amérique du Sud de se projeter sur le plan géopolitique et contribue à la construction d'un nouveau pôle dans le système international.

Mot-Clés: Unasur. Politique étrangère brésilienne. Régionalisme. Relations internationales. Amérique du Sud.

Tiago Nery - Doutor em ciência política pelo Instituto de Estudos Sociais e Políticos da Universidade do Estado do Rio de Janeiro (IESP-UERJ). Especialista em Políticas Públicas e Gestão Governamental do Estado do Rio de Janeiro (EPPGG-RJ). Principais temas de interesse: Relações Internacionais, Bilaterais e Multilaterais; Política externa brasileira; Política internacional; Economia política internacional e América Latina contemporânea. Publicações recentes: Partidos políticos e política externa brasileira: breve análise das propostas do PSDB e do PT nas eleições de 1994 a 2014. Observador on-line, v. 9, p. 1-19, 2014; Democracia e desigualdade nos Estados Unidos. Revista Brasileira de Ciências Sociais (Impresso), v. 27, p. 244-250, 2012; O significado e os desafios do novo-desenvolvimentismo. Princípios (São Paulo), v. 119, p. 47-49, 2012. 
